\title{
A STUDY ON THE INFLUENCE MECHANISM OF VANDALISM INTENTION OF OUTBOUND TOURISTS BASED ON EXTENDED THEORY OF PLANNED BEHAVIOR MODEL
}

\author{
LIN, M. S. ${ }^{1,2}-$ YU, H. ${ }^{2}-$ ZENG, Y. F. ${ }^{1}-$ XIAO, X. N. ${ }^{1 *}-$ WANG, K. Y. ${ }^{2}$ \\ ${ }^{1}$ College of Tourism, Fujian Normal University \\ 1 Science and Technology Road50117 Fuzhou, P. R. China \\ ${ }^{2}$ Institute of Geographic Sciences and Natural Resources Research, Chinese Academy of \\ Sciences, 11 A Datun Road, 100101 Beijing, P. R. China \\ *Corresponding author \\ e-mail: xinni4@hotmail.com; phone: +86-591-2286-8726 \\ (Received $17^{\text {th }}$ Jun 2018; accepted 22 $2^{\text {nd }}$ Aug 2018)
}

\begin{abstract}
Tourist vandalism has been a common phenomenon in different countries and regions with the rapid development of tourism industry. It is deteriorating the quality of recreational environment, and hazarding the safety. Current researches implied that the unified understanding of the concept of vandalism had not yet formed, basic theoretical framework research was still weak and the antecedent factors of vandalism and its generating mechanism had not been paid enough attention to, which greatly affected the management of tourist vandalism. Therefore, adopting the extended Theory of Planned Behavior (TPB) perspective, this paper constructs the theoretical model of tourist vandalism. Then, using Structural Equation Models (SEM), taking tourists from Mainland to Taiwan as the case study, combined with questionnaire data, the study seeks to examine the influence factors of vandalism and its generating mechanism. The study found out that: (1) past behavior has significant positive effects on behavior intention, while subjective norm and perceived behavioral control have no significant positive effect on behavior intention; (2) past behavior has a significant positive effect on behavior intention, while subjective norm and perceived behavioral control have no significant positive effects on behavioral attitude; (3) environmental awareness has a significant positive effect on behavioral attitude, subjective norm, past behavior, while has no significant positive effect on perceived behavioral control. To conclude, environmental awareness and past behavior are applied to understand tourist vandalism and makes contribution to the tourist vandalism literature. Consequently, the paper suggests that family, schools and the educational institution should provide targeted training to outbound tourists to guide their attitude and clarify the concept of tourist vandalism and its negative influences through establishment of vandalism list to help tourists recognize and avoid vandalism in the future.
\end{abstract}

Keywords: environmental awareness, Mainland, Taiwan, structural equation models

\section{Introduction}

With the rapid development of tourism, Tourist vandalism has become widely discussed in various countries and regions (Bhati and Pearce, 2016). Whether vandalism is caused by independent tourists or group tourists, intentional or unintentional, accidental or repeated acts, it damages the surrounding environment and resources quality, public or private property, recreational safety, etc. Tourist vandalism greatly increases the management costs of tourism destinations. The annual repair costs due to tourist vandalism were up to 79.2 million US dollars in National Parks of USA and the cleaning and maintenance reached the amount of 18.8 million US dollars (Johnson et al., 1996); 10\% of the annual budget for recreation forest in Beth, Canada is used to recover the damages caused by tourists; 9\% of the total annual budget accounts for cleaning and maintenance for Yangmingshan Park in Taiwan area (Yang et al., 2013). 
Obviously, tourist vandalism has always been one of the main factors to worsen the quality of recreational environment and safety (Chang et al., 1995).

Different disciplines have different understanding of tourist vandalism. Social behavioral studies mainly recognize tourist vandalism from the perspective of social behavior standards, legal provisions, and moral deviations; Environmental Psychology perceives the message of vandalism from the surrounding environment and personal psychological attitudes; Environmental Ethology focuses on the interaction between environmental information and vandalism from the emotions and attitudes of tourists response to the environment; Recreational behavior theory emphasizes the influence of physical and psychological needs and external human, social, and natural factors, and determines the intention to vandalism through the cognitive process of the surrounding environment (Kaplan, 1983). Based on the definition of different disciplines, the concepts similar to tourist vandalism include tourist deviant behavior (Mills et al., 1978), dysfunctional behavior (Daunt et al., 2012), depreciative behavior (Ibitayo et al., 1996), misbehavior (Fullerton et al., 2004), uncivilized behavior (Li et al., 2002), etc. These similar concepts have, to a certain extent, outlined the current state of negative impact of tourist behavior on the natural and humanistic social environment of tourism destinations. However, these concepts have not reflected the degree of harm caused by tourist negative behavior, and whether it constitutes a crime or not. This is not conducive to tourists' understanding and control of their negative behaviors.

Some scholars have pointed out that tourist behavior is a comprehensive manifestation of a series of psychological and physical behaviors formed by interaction between tourists and the new environment. It can be expressed by the equation $\mathrm{B}=\mathrm{f}(\mathrm{P}, \mathrm{E})$, that is, tourist behavior is shaped by personal and environmental factors (Lewin, 1951). Based on the above equation, this paper defines tourist vandalism as tourists' improper behavior that violated social norms resulted from inadequate or excessive stress on the changes when tourists engaged in recreational activities, in an unconventional context. Although the behavior may not necessarily constitute a crime, it does harm the natural and human social environment of the tourist destination (Bhati and Pearce, 2016) Typical tourist vandalism includes graffiti, littering, throwing food to animals, damaging the vegetation, snapping off coral, noise making, improper dressing code, damaging recreational property, etc. (Chang et al., 1995).

After reviewing the relevant domestic and foreign literatures of tourist vandalism, it has been found out that academic attention focused on vandalism behaviors of tourists (Weaver, 2006), theoretical basis (Bhati, 2014), influential factors (McCaghy, 2008), motivation (Crotts, 2003), behavioral control (Cohen, 1973), etc. Foreign researchers and researchers form Hongkong and Taiwan have made fruitful achievements on the characteristics of tourist vandalism (Chang et al., 1995), macro (social, economic and environmental design) and micro (physiological, developmental, psychological) influential factors (Chang et al., 2003; Hou et al., 1998; Huang et al., 2016), Environment design ecological explanations of vandalism, Human ecological explanations of vandalism, Behavioral ecological explanations of vandalism, Integrative ecological explanations to vandalism, Cohen typology, situational crime, environmental design, technical and non-technical preventive approaches (Bhati and Pearce, 2016) etc. But Chinese scholars have not yet reached uniformed understanding on the concept and research subject of tourist vandalism $(\mathrm{Li}, 2012)$. Due to the sensitive topics of tourist vandalism, the complexity of classification, and the difficulties in obtaining survey data, researchers are more likely to adopt obscure words like uncivilized behaviors, 
inappropriate behaviors to replace the word vandalism, which leads to weak basic of theoretical researches. The current research mainly focuses on the influential factors and motivations of uncivilized behavior, with the research achievements scattered in areas such as outbound tourism (Qiu, 2016) and ecotourism (Gao, 2003), which indicates the huge gap with foreign researches. It is urgently necessary to unify conceptual understanding of tourist vandalism and construct psychological and environmental science research paradigms, so as to promote the breadth and depth of the research.

Based on Theory of Planned Behavior (TPB) in psychology, this study expands the model to construct a framework of tourist vandalism. Taking the tourists visiting Taiwan as an example, the Structural Equation Models (SEM) is adopted to verify the influencing factors and mechanisms of vandalism. Furthermore, the study proposes counter measures to promote the in-depth study of tourist vandalism in theory and practice.

\section{Literature review and research hypothesis}

\section{Theory of planned behavior}

Theory of Planned Behavior (TPB), a derivative theory of Reasoned Action (TRA), was proposed by Ajzen to explain the process of individual decision-making (Ajzen, 1991). TPB holds the idea that human behavior is the result of deliberate planning, which can explain how people change their behavior patterns. TPB also can be used to predicate human behavior. In the 185 studies of Armitage and Conner (2001), TPB can explain $39 \%$ of behavior intention and $27 \%$ of behavior variance, so it is often used in the study of tourist behavior, such as tourist low-carbon travel decisions (Bamberg et al., 2003), ecological choices (Greaves et al., 2013; Kaiser, 2003), intention to participate in low-carbon tourism (Hu, 2014), green hotel consumption options (Xie, 2016), and pro-environmental behavior (López-Mosquera, 2016), etc. TPB has a better explanation for tourist behavior intention (Lin et al., 2016; Qiu, 2016).

In TPB, Attitude toward the behavior (AT) is a determinant factor of behavioral intention (BI). Salient Beliefs are cognitive and emotional foundations of attitude toward the behavior (AT), Subjective norm (SN), and Perceived behavioral control (PBC) (Ajzen, 1991). TPB assumes that behavioral intention covers the motivation for behavior. It reflects people's willingness to try or plan to work hard for something, that is, the stronger a person's intention to act, the more likely the action will happen (Duan, 2008). TPB further assumes that behavioral intention is mainly determined by AT, SN, and PBC (Cui, 2010). Lin et al. (2016) constructed a conceptual framework of tourist civilized behavioral intention and civilized behavior attitude based on TPB. It was found that there was a significant positive correlation between tourists' attitudes, travel times and tourist civilized behavioral intention; and there was a significant positive correlation between tourists' jobs, educational background, travel times and tourists' civilized behavior attitude.

Based on above description, the following hypothesis is proposed:

H1. The behavioral attitude has a positive effect on tourist's intention of vandalism.

Xie (2016) studied the decision-making mechanism of consumers choosing to stay in a green hotel based on TPB. The study proposed that behavioral attitude is the most important factor. Subjective norms not only directly affect behavioral intentions, but also indirectly influence behavioral intentions through behavioral attitudes and perceived behavioral control. Qiu $(2017,2016)$ introduced moral norms and local 
attachment based on TPB, and constructed a model of outbound tourists civilized behavior intention mechanism. It is confirmed that subjective norms, perceived behavior control, moral norms, and local attachment all indirectly affect the intentions of outbound tourists civilized behavior through behavioral attitudes. Meanwhile, subjective norms not only directly affect behavioral attitudes, but also indirectly affect behavioral attitudes through moral norms; behavioral attitudes are the most important factor in driving intentions of outbound tourists' civilized behaviors. Based on the above discussion, the following hypotheses can be proposed:

H2. Subjective norms have a positive effect on tourist's intention of vandalism.

H3. Perceived behavioral control has a positive effect on tourist's intention of vandalism.

H4. Subjective norms have a positive effect on tourist's attitude toward vandalism.

H5. Perceived behavioral control has a positive effect on tourist's attitude toward vandalism.

H6. Perceived behavioral control has a positive effect on subjective norms of tourist's vandalism.

\section{Past behavior and behavioral intentions}

"More than $90 \%$ of people's daily activities are habitual behaviors" (Li, 2007). Ajzen (1991) suggested adding past behaviors to perceived behavioral control of TFB which could better predict behavior. Ouellette and Wood (1998) pointed out that past behaviors had an impact on future behaviors in two phases. Good behaviors repeatedly occur in a specific behavioral context. The frequency of past behaviors reflects the habit strength and has direct influence on future performance (Ouellette and Wood, 1998). Christina et al. (2004), after studying the tourist littering behavior, pointed out that there was a very significant relationship between past behavior and behavioral intentions for those who did not have recycling habits. Compared with behavioral attitudes, subjective norms, and perceived behavioral control variables, past behaviors can better explain behavioral variances, and people's past behaviors mainly influence their behaviors through intermediary variables such as behavioral attitudes and behavioral intentions (Ajzen, 2005). Therefore, it is necessary to include tourists' past vandalism into the theoretical framework of tourist vandalism and put forward the following hypothesis:

H7. Past behaviors have a positive effect on tourist's intention of vandalism.

H8. Past behaviors have a positive effect on tourist's attitude toward vandalism.

H9. Past behaviors have a positive effect on the subjective norms of tourist's vandalism.

H10. Past behaviors have a positive effect on perceived behavioral control of tourist's vandalism.

\section{Environmental awareness and behavioral intention}

Environmental Awareness (EA), also known as "Ecological Awareness", "Environmental/ Ecological Literacy" or "Environmental/Ecological Concern" (Dunlap et al., 1978). Though there is no uniformed definition at home and abroad (Roth, 1992), a common sense still exits that EA reflects relationship between man and nature (Hwang, 2000). According to the $B=f(P, E)$ formula, environmental awareness is one important factor influencing tourist vandalism. Many tourists may think their vandalism reasonable, and make excuses for their behavior, or they are completely unaware of 
their mistakes (Chang et al., 2003). Studies have shown that tourists with better environmental awareness would have incentives to protect the environment (Hwang et al., 2000). Wang (2010) applied TPB to the study of the relationship between environmental awareness and environmental behavior of tourists, and found out that there was a significant correlation between environmental awareness and environmental behavior of tourists. The key factors of environmental awareness influencing environmental behavior had been identified. Lin et al. (2014) surveyed that there was a significant positive correlation between the environmental awareness and tourists' behavior. Based on Widegren (Bamberg, 2003), Corral-Verdugo et al. (2008) and other related research results, the following research hypotheses are proposed:

H11. Environmental awareness has a positive effect on tourist's attitude toward vandalism.

H12. Environmental awareness has a positive effect on tourist's past vandalism.

H13. Environmental awareness has a positive effect on subjective norms of tourist's vandalism.

H14. Environmental awareness has a positive effect on perceived behavioral control of tourist's vandalism (Fig. 1).

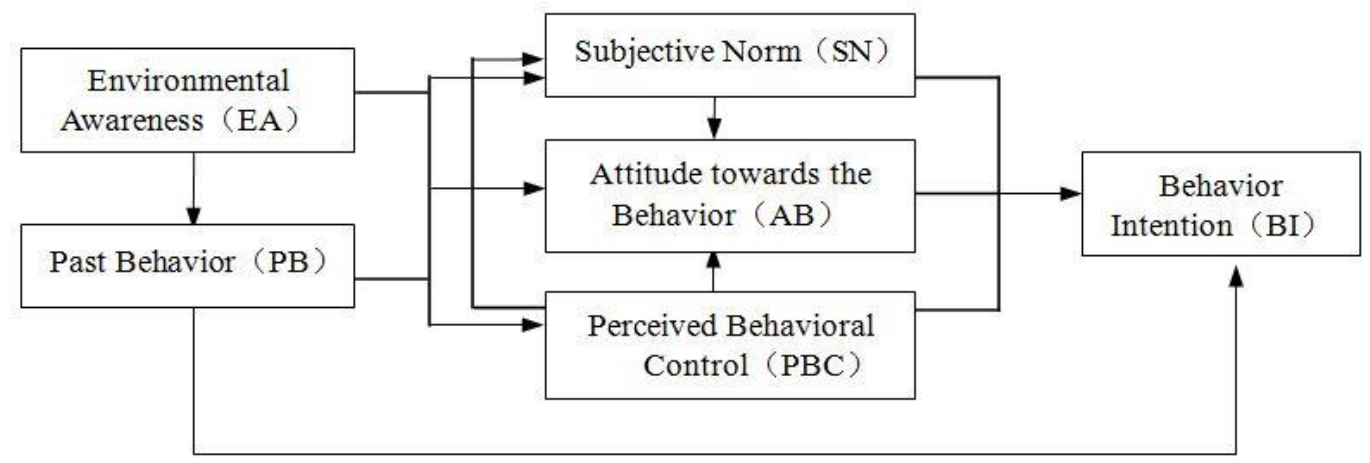

Figure1. Conceptual framework of vandalism intention

\section{Methodology}

\section{Research methods}

Based on the tourist vandalism and environmental awareness scale, the questionnaire was divided into two parts: the demographic characteristics of tourists and the main body of the questionnaire. The demographic characteristics of tourists include the tourist's place of residence, age, gender, monthly income, occupation, educational background, and travel times. Tourist vandalism includes "graffiti, littering, throwing food to animals, damaging the vegetation, snapping off coral, noise making, improper dressing code, damaging recreational property" (Xu, 2014). Questionnaire topics cover tourists' attitude toward vandalism, subjective norms, perceived behavioral control, past vandalism, environmental awareness, and vandalism intentions. The questions refer to Bamberg and Ajzen (2003), Gao (2003), Li (2007), Dunlap (1978, 2008), Luo (2007) in TPB and environmental awareness measurement (Table 1). The questionnaire was measured by 5-points Likert-type scale, and the respondents were asked about their level of agreement. In order to avoid hurried responses from the visitors, the fuzzy options of "don't know" and "general" were removed and respondents were required to make choices, with actual scores ranging from 1 to 4 points. 
Table1. Questionnaire of vandalism

\begin{tabular}{|c|c|c|c|}
\hline Variable & Measurement index & Mean & Standard deviation \\
\hline \multirow{3}{*}{$\begin{array}{l}\text { Attitude towards the } \\
\text { behavior } \\
\text { (AB) }\end{array}$} & AB1 It's fine to have vandalism in Taiwan & 3.03 & 0.883 \\
\hline & AB2 It's allowed to have vandalism in Taiwan & 2.93 & 0.965 \\
\hline & $\begin{array}{c}\text { AB3 It's reasonable to have vandalism in } \\
\text { Taiwan }\end{array}$ & 3.11 & 0.919 \\
\hline \multirow{3}{*}{$\begin{array}{l}\text { Subjective norm } \\
(\mathrm{SN})\end{array}$} & $\begin{array}{l}\text { SN1 My family and relatives believe that I can } \\
\text { have vandalism in Taiwan }\end{array}$ & 2.96 & 0.972 \\
\hline & $\begin{array}{l}\text { SN2 My friends believe that I can have } \\
\text { vandalism in Taiwan }\end{array}$ & 2.85 & 0.882 \\
\hline & $\begin{array}{l}\text { SN3 My relatives and family believe that I can } \\
\text { have vandalism in Taiwan }\end{array}$ & 2.88 & 0.880 \\
\hline \multirow{3}{*}{$\begin{array}{c}\text { Perceived behavioral } \\
\text { control } \\
\text { (PBC) }\end{array}$} & $\begin{array}{l}\text { PBC1 It is entirely up to me to make vandalism } \\
\text { in Taiwan }\end{array}$ & 2.84 & 0.981 \\
\hline & $\begin{array}{l}\text { PBC2 There is no control to make vandalism in } \\
\text { Taiwan }\end{array}$ & 2.91 & 0.962 \\
\hline & $\begin{array}{l}\text { PBC3 I could behave like a vandalist anytime in } \\
\text { Taiwan }\end{array}$ & 2.76 & 0.983 \\
\hline \multirow{3}{*}{$\begin{array}{l}\text { Behavior intention } \\
\text { (BI) }\end{array}$} & $\begin{array}{l}\text { BI1 How likely does vandalism occur in } \\
\text { Taiwan? }\end{array}$ & 2.80 & 0.874 \\
\hline & $\begin{array}{l}\text { BI2 How willful does vandalism occur in } \\
\text { Taiwan? }\end{array}$ & 2.87 & 0.884 \\
\hline & $\begin{array}{l}\text { BI3 At what probability does the vandalism } \\
\text { occur in Taiwan? }\end{array}$ & 2.80 & 0.873 \\
\hline \multirow{2}{*}{$\begin{array}{l}\text { Past behavior } \\
\text { (PB) }\end{array}$} & $\begin{array}{l}\text { PB1 Vandalism happened last time I visited } \\
\text { Taiwan }\end{array}$ & 2.93 & 0.950 \\
\hline & $\begin{array}{l}\text { PB2 Vandalism happened a lot last time I visited } \\
\text { Taiwan }\end{array}$ & 3.01 & 0.898 \\
\hline \multirow{3}{*}{$\begin{array}{l}\text { Environmental } \\
\text { awareness } \\
\text { (EA) }\end{array}$} & $\begin{array}{l}\text { EA1 Natural self-regulation is strong enough to } \\
\text { withstand the effects of modern industrial society }\end{array}$ & 2.24 & 0.905 \\
\hline & $\begin{array}{l}\text { EA2 Humans can develop and change the natural } \\
\text { environment in order to meet their own needs }\end{array}$ & 2.32 & 0.859 \\
\hline & $\begin{array}{l}\text { EA3 Humans will eventually understand natural } \\
\text { laws to fully control the natural world }\end{array}$ & 2.28 & 0.876 \\
\hline
\end{tabular}

Descriptive statistics of the questionnaires were collected by SPSS22.0 software to obtain the mean scores and standard deviations of each test topic. Correlation analysis was carried out on each test topic to obtain the correlation coefficient. Based on this, factor analysis was conducted to obtain the KMO value of the questionnaire and the factor loadings of each item. Reliability analysis was conducted to obtain the Cronbach's $\alpha$ coefficient of each variable and each item.

This study investigated the influence mechanism of tourist vandalism. To test the proposed model, the statistical tool Amos22.0 was used to conduct Structural Equation Models (SEM) analysis. Combined with the questionnaire data, the hypothetical model was fitted and tested, and was modified by removing insignificant path links.

Composite reliability was assessed by Equation 1, and the average variance extracted (AVE) values were acquired by Equation 2. 


$$
\begin{gathered}
C R=\frac{\left(\sum_{i=1}^{k} \lambda_{i}\right)^{2}}{\left(\sum_{\mathrm{i}=1}^{k} \lambda_{i}\right)^{2}+\sum_{\mathrm{i}=1}^{k} e_{i}} \\
A V E=\frac{\sum_{\mathrm{i}=1}^{k} \lambda_{i}^{2}}{\sum_{\mathrm{i}=1}^{k} \lambda_{i}^{2}+\sum_{\mathrm{i}=1}^{k} e_{i}}
\end{gathered}
$$

In Equations 1 and 2, $k$ means the number of measured corresponding factors, $\lambda_{k}$ means the true variance, and $e_{k}$ means error variance.

\section{Data collection}

Considering the diversity of tourists, representativeness of tourist vandalism, and availability of data, this study takes Chinese tourists who are visiting Taiwan as an example (Table 1). Taiwan could make a typical case. Chinese traditional culture is deeply penetrated into the society of Taiwan. On the other hand, Taiwan had been under Japan's rule for 50 years, and it is also westernized. Due to the political and historical reasons, Chinese visitors visiting Taiwan can be regarded as domestic tourism in theory, but it is actually viewed as outbound tourism in practice. Therefore, it is meaningful to take Chinese visitors visiting Taiwan as an example to study the influence factors and mechanism of tourist vandalism, which will contribute a lot to the prevention of tourist vandalism in domestic and outbound tourism.

This study chose to cooperate with the Hong Kong, Macao and Taiwan Affairs Offices of the Fujian Provincial Tourism Administration from September to October of 2017, peak time of mid-autumn holiday, to conduct a questionnaire survey at Fuzhou Changle International Airport and Pingtan cruise to Taiwan. A simple random sampling method was adopted. 200 questionnaires were issued each month. 5 copies had been sent to each Taiwan tour each time. 400 questionnaires were distributed to backpack tourists, 367 were returned and with a final example of 316 (79\% response rate).

\section{Data analysis and research results}

\section{Demographic characteristics description}

This study measured 17 items and the 400 sample size estimate by Cochran method. Also, structural equation analysis is used to assess the overall fitness of the model and examine the statistical significant of each hypothesis (Wu, 2009). 316 respondents were mainly from Fujian Province, only $27.53 \%$ respondents were non-Fujian Province tourists. $51.90 \%$ were female. They are predominately young, with $37.97 \%$ in their $20 \mathrm{~s}$ and $52.53 \%$ in their 30s. Most respondents received bachelor degree $(44.93 \%)$ or got education to senior middle/professional college $(35.44 \%)$. $58.86 \%$ of respondents monthly earned 2000-3999 yuan. In terms of the occupation of tourists, most of them work for public institutions $(41.14 \%)$, corporate staff $(33.23 \%)$ and civil service (14.87\%); $77.22 \%$ of respondents visited Taiwan for the first time, and $22.15 \%$ tourists visited Taiwan for the second time; $84.18 \%$ of respondents visited Taiwan by group 
tour, only $15.82 \%$ chose independent travel. The sample data satisfy the assumption of normal distribution as each indicator's skewness are between -0.60 and 0.842 , the corresponding the absolute value is less than 3; the kurtosis are between -0.127 and 1.002, the corresponding absolute value is less than 8 (Wu, 2009).

\section{Common method variance}

Harman's single-factor test was used to perform exploratory factor analysis on the variables of interest. The results showed that the variance interpretation ratio of the first unrotated factor was only $39.79 \%$ and less than $50 \%$, indicating that CMV was Acceptable range; the maximum correlation coefficient of all variables is 0.85 , less than 0.90 , the CMV of the displayed data is not obvious. Therefore, the common method bias of survey data is not a pervasive issue.

\section{Reliability and validity test}

Using SPSS22.0, we scrutinized the overall reliability was 0.923 , and the Cronbach's alpha value of each latent variable was between 0.783 and 0.923 (Table 2), which exceeded acceptable thresholds of 0.7 , thus indicating that the scale was reliable.

Table 2. Reliability and validity test of the scale

\begin{tabular}{|c|c|c|c|c|c|c|}
\hline $\begin{array}{c}\text { Latent } \\
\text { variables }\end{array}$ & $\begin{array}{c}\text { Measurement } \\
\text { index }\end{array}$ & $\begin{array}{l}\text { Factor } \\
\text { loading }\end{array}$ & t-value & Cronbach's $\alpha$ & C.R. & AVE \\
\hline \multirow{3}{*}{$\begin{array}{c}\text { Attitude } \\
\text { towards the } \\
\text { behavior }(\mathrm{AB})\end{array}$} & $\mathrm{AB} 1$ & 0.931 & - & \multirow{3}{*}{0.906} & \multirow{3}{*}{0.914} & \multirow{3}{*}{0.780} \\
\hline & $\mathrm{AB} 2$ & 0.777 & 18.705 & & & \\
\hline & $\mathrm{AB} 3$ & 0.933 & 27.542 & & & \\
\hline \multirow{3}{*}{$\begin{array}{l}\text { Subjective norm } \\
\text { (SN) }\end{array}$} & SN1 & 0.806 & - & \multirow{3}{*}{0.889} & \multirow{3}{*}{0.896} & \multirow{3}{*}{0.742} \\
\hline & SN2 & 0.879 & 18.055 & & & \\
\hline & SN3 & 0.896 & 18.486 & & & \\
\hline \multirow{3}{*}{$\begin{array}{c}\text { Perceived } \\
\text { behavioral } \\
\text { control (PBC) }\end{array}$} & PBC1 & 0.946 & - & \multirow{3}{*}{0.932} & \multirow{3}{*}{0.913} & \multirow{3}{*}{0.778} \\
\hline & $\mathrm{PBC} 2$ & 0.798 & 19.827 & & & \\
\hline & PBC3 & 0.895 & 25.463 & & & \\
\hline \multirow{3}{*}{$\begin{array}{c}\text { Behavior } \\
\text { intention (BI) }\end{array}$} & BI1 & 0.955 & - & \multirow{3}{*}{0.911} & \multirow{3}{*}{0.934} & \multirow{3}{*}{0.825} \\
\hline & $\mathrm{BI} 2$ & 0.863 & 24.351 & & & \\
\hline & BI3 & 0.904 & 27.374 & & & \\
\hline \multirow{2}{*}{$\begin{array}{l}\text { Past behavior } \\
\text { (PB) }\end{array}$} & PB1 & 0.876 & - & \multirow{2}{*}{0.853} & \multirow{2}{*}{0.854} & \multirow{2}{*}{0.746} \\
\hline & PB2 & 0.851 & 17.321 & & & \\
\hline \multirow{3}{*}{$\begin{array}{c}\text { Environmental } \\
\text { awareness (EA) }\end{array}$} & EA1 & 0.747 & - & \multirow{3}{*}{0.783} & & \\
\hline & EA2 & 0.689 & 10.579 & & 0.783 & 0.547 \\
\hline & EA3 & 0.780 & 11.336 & & & \\
\hline
\end{tabular}

In terms of construct validity, first, we completed the reviews of literature to gain each construct. Second, we employed the pilot studies and the factor analysis method was adopted. For structural validity, the factor with the eigenvalue greater than 1 was retained. The cumulative variance contribution rate was $75.32 \%$, the KMO was 0.885 , and the Bartlett's sphere test had a significance of 0.000 . The normalized load values 
corresponding with each latent variable are between 0.689-0.946, all loadings and corresponding t-value is between 10.579 to 27.542 , the composite reliability is between 0.783-0.934, and the average variance extracted (AVE) for each scale is between 0.5470.825. Each AVE exceeded Fornell and Larcker's (1981) suggested minimum value of .50 , which indicates convergence validity was good.

Analysis of the goodness fit indexes suggested good model fit $\left(\mathrm{X}^{2} / \mathrm{df}=2.473\right.$, Root Mean Square Residual $[\mathrm{RMR}]=0.041$, Root mean square error of approximation $[$ RMSEA $]=0.068$, goodness-of-fit indexes $[\mathrm{GFI}]=0.914, \mathrm{TLI}=0.952$, normed fit index $[\mathrm{NFI}]=0.940$, Incremental Fit Index $[\mathrm{IFI}]=0.963$, comparative fit index $[\mathrm{CFI}]=0.963)$. The fit statistics shows that the overall research model provides a good fit with the data $(\mathrm{Wu}, 2009)$.

\section{Structural equation models analysis}

Using Amos22.0, The fit index met the corresponding requirement $(\mathrm{X} 2 / \mathrm{df}=2.456$, $\mathrm{RMR}=0.041, \mathrm{RMSEA}=0.068, \mathrm{GFI}=0.914, \mathrm{TLI}=0.952, \mathrm{NFI}=0.940, \mathrm{IFI}=0.963$, $\mathrm{CFI}=0.963)$, and supported nine hypotheses $(\mathrm{H} 1, \mathrm{H} 4, \mathrm{H} 6, \mathrm{H} 7, \mathrm{H} 9, \mathrm{H} 10, \mathrm{H} 11, \mathrm{H} 12$, $\mathrm{H} 13$ ), while $\mathrm{H} 2, \mathrm{H} 3, \mathrm{H} 5, \mathrm{H} 8, \mathrm{H} 14$ have been rejected (Table 3).

Table 3. Result of hypothesis test

\begin{tabular}{ccc|c|c|c}
\hline \multicolumn{2}{c|}{ Hypothesis path } & & Path coefficient & t value & Result \\
\hline $\mathrm{H} 1: \mathrm{AB}$ & $\rightarrow$ & $\mathrm{BI}$ & $0.259^{* *}$ & 2.636 & Support \\
$\mathrm{H} 2: \mathrm{SN}$ & $\rightarrow$ & $\mathrm{BI}$ & -0.003 & -0.028 & Denial \\
$\mathrm{H} 3: \mathrm{PBC}$ & $\rightarrow$ & $\mathrm{BI}$ & -0.03 & -0.035 & Denial \\
$\mathrm{H} 4: \mathrm{SN}$ & $\rightarrow$ & $\mathrm{AB}$ & $0.607^{* * *}$ & 7.111 & Support \\
$\mathrm{H} 5: \mathrm{PB}$ & $\rightarrow$ & $\mathrm{AB}$ & 0.052 & 0.757 & Denial \\
$\mathrm{H} 6: \mathrm{PBC}$ & $\rightarrow$ & $\mathrm{SN}$ & $0.178^{*}$ & 2.451 & Support \\
$\mathrm{H} 7: \mathrm{PB}$ & $\rightarrow$ & $\mathrm{BI}$ & $0.405^{* *}$ & 2.999 & Support \\
$\mathrm{H} 8: \mathrm{PB}$ & $\rightarrow$ & $\mathrm{AB}$ & 0.013 & 0.137 & Denial \\
$\mathrm{H} 9: \mathrm{PB}$ & $\rightarrow$ & $\mathrm{SN}$ & $0.553^{* * *}$ & 9.124 & Support \\
$\mathrm{H} 10: \mathrm{PB}$ & $\rightarrow$ & $\mathrm{PBC}$ & $0.762^{* * *}$ & 8.837 & Support \\
$\mathrm{H} 11: \mathrm{EA}$ & $\rightarrow$ & $\mathrm{AB}$ & $0.216^{* *}$ & 2.730 & Support \\
$\mathrm{H} 12: \mathrm{EA}$ & $\rightarrow$ & $\mathrm{PB}$ & $0.470^{* * *}$ & 5.474 & Support \\
$\mathrm{H} 13: \mathrm{EA}$ & $\rightarrow$ & $\mathrm{SN}$ & $0.444^{* * *}$ & 5.917 & Support \\
$\mathrm{H} 14: \mathrm{EA}$ & $\rightarrow$ & $\mathrm{PBC}$ & -0.064 & -0.736 & Denial \\
\hline
\end{tabular}

$* * * \mathrm{P}<0.001, * * \mathrm{P}<0.01, * \mathrm{P}<0.05$. AB: Attitude towards the behavior, SN: Subjective norm, PBC: Perceived behavioral control, BI: Behavior intention, PB: Past behavior, EA: Environmental awareness

The model has been modified by removing insignificant path links ( $\mathrm{Wu}, 2009)$. The corrected fit index was: $\mathrm{X} 2 / \mathrm{df}=2.358, \mathrm{RMR}=0.043, \mathrm{RMSEA}=0.066$, GFI $=0.914$, $\mathrm{TLI}=0.955, \mathrm{NFI}=0.939$, IFI value $=0.964, \mathrm{CFI}=0.964$. Meanwhile, the postcorrection fit index was good and the initial model has been improved. The revised model was more concise than the initial model (Fig. 2). 


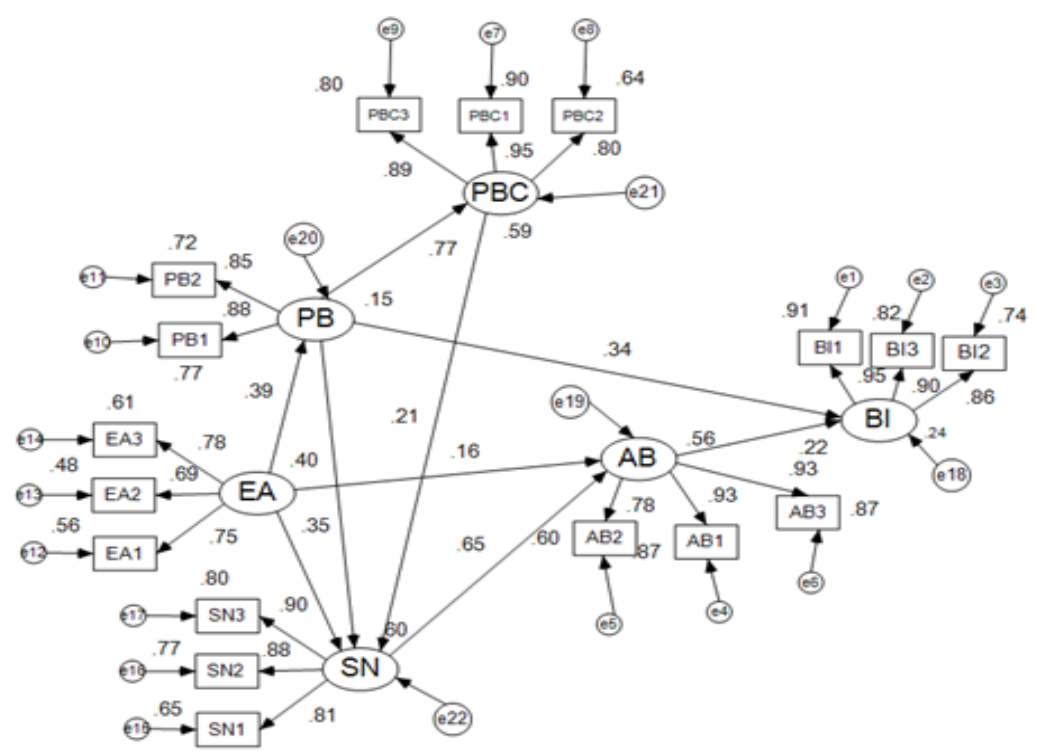

Figure 2. Map of vandalism intention of tourists from Mainland to Taiwan. (AB: Attitude towards the behavior, SN: Subjective norm, PBC: Perceived behavioral control, BI: Behavior intention, PB: Past behavior, EA: Environmental awareness)

\section{Conclusions and discussions}

\section{Conclusions}

First, tourist's attitudes toward vandalism and past vandalism have a significant positive effect on behavioral intentions, which is consistent with the original assumptions of theoretical models of planned behaviors. The results also reflect in Lin's (2016) research on the formation mechanism of the tourists to Taiwan civilized behaviors intention and the findings of Qiu (2017) on the influencing mechanism of civilized tourists behavior intentions. The coefficient of influence on the behavioral intention of the past behavior (0.34) was significantly higher than that of the behavioral attitude on the behavioral intention (0.22). It shows that tourists past vandalism would significantly influence their intention to repeat their vandalism.

Second, the subjective norms of tourist vandalism and perceived behavioral control have no direct positive influence on behavior intentions, which explains that the attitude of peers and the willingness of tourists to act vandalism have not directly positive affected their vandalism intention, while they indirectly influence behavioral intentions through behavioral attitudes. This proves Qiu's (2017) study on perceived behavior control of the civilized tourists' behaviors indirectly affecting behavioral intentions through behavioral attitudes. When the subject of the study is macroscopic, vague, and does not have much to do with tourists' own interests, such as ecotourism behaviors, civilized tourist behavior, and green purchasing behavior, the approval attitude of the peers has a direct positive effect on tourists' behavior intentions. On the opposite, when the subject of the study is quite sensitive and more related to the interests of tourists, like, graffiti, littering, throwing food to animals, snapping off the vegetation and coral, noise making, improper dressing, damaging recreational property and other vandalism, then the attitudes of the peers do not have a direct positive effect on the tourist behavior intentions. And the approval attitude of the local residents of the tourism destination may become an important factor that directly affects tourist vandalism intention. The 
positive effects of perceived behavioral control on behavioral attitudes are not significant, but they indirectly affect behavioral attitudes through subjective norms. This is different from the results of Qiu (2017) research that these two variables are multiinfluenced. It shows that the attitudes of the peers have a positive impact on the tourist vandalism, furthermore affects the behavioral attitudes and behavioral intentions.

Third, past behavior has positively influenced behavioral intentions, subjective norms and perceived behavioral control, but the positive impact on behavioral attitudes is not significant. The findings are basically consistent with Ajzen's (1991) expansion research on the TPB, while are not consistent with the findings of Li (2007). Past behavior has a significant positive effect on behavioral intentions, but the impact on behavioral attitudes is not significant, possibly due to the Face issues. Tourist vandalism are kinds of sensitive and negative behaviors, although tourists respond positively. However, in decision-making process of specific behavioral intentions, they are deeply influenced by past behaviors, and may deliberately avoid the choice of true behavioral intentions.

Fourth, environmental awareness has positive influence on past behaviors, subjective norms, and behavioral attitudes, but the impact on perceived behavioral control is not significant. This is consistent with Lin's (2014) findings of significant correlation with environmental awareness and tourism behavior, and has deepened the research on the mechanism of environmental awareness affecting tourism behavior. There are mainly two ways how environmental awareness influences behavior intentions: one is indirect influence on behavioral intentions by past behavior; the other is indirect influence on behavioral intentions through subjective norms and behavioral attitudes. Thus, environmental awareness is an important latent variable for outbound tourist vandalism. In addition, the direct impact of environmental awareness on perceived behavioral control is not significant. The reason is that environmental awareness reflects the tourists' opinions on the relationship between people and nature, which can directly affect behavior intentions and the behavior itself. Therefore, through the direct influence on the past behavior, it will indirectly affect the perceived behavioral control.

In conclusion, based on the conceptual formula $B=f(P, E)$, this study further defines the connotation and extension of tourist vandalism, and provides a theoretical basis for the study of vandalism behaviors of domestic and foreign tourists. Furthermore, variables such as environmental awareness and past behaviors are introduced into the modified tourist vandalism intention model, which further verifies the reliability of the planned behavior theory to explain the mechanism of tourist vandalism, and further clarifies the influence mechanism of environmental awareness on past behaviors, subjective norms, and behavioral attitudes. This study has important reference significance for the study of the mechanism of tourist vandalism. It also promotes the perfection of the theory and application of planned behavior theory in Chinese context.

\section{Discussions}

In 2016, the number of Chinese outbound tourists reached 122 million, and the tourists spent 109.8 billion US\$ while traveling abroad (Qiu, 2017). The huge outbound tourism market is not only for tourist's personal leisure and holiday activities, but also bears its social awareness and responsibility. Based on the above research, we can unify the individual consumption behavior of outbound tourists and social responsibility from the following three aspects. Such managerial implications foster broader implications for public policy makers. That is, while it may be beneficial for service companies to 
train employees in methods of misbehavior management and deterrence, from a public policy perspective it would appear fruitful to educate customers.

(1) Face the urgent needs of scientific research on tourist vandalism. Tourist vandalism is not a unique phenomenon to China's outbound tourists. The developed countries have experienced various degrees of vandalism during the rapid development of tourism. The key is how to propose appropriate governance programs through scientific research to change the personal vandalism of a few tourists as soon as possible to avoid the formation of group phenomenon. The best reference is Japan's approach to vandalism of outbound tourists in the 1980's. Therefore, there is an urgent need to clarify the concept and characteristics of tourist vandalism in the Chinese context, and establish a black list of outbound tourist behaviors for different tourist destinations. According to the government notices of " 20 uncivilized behaviors of domestic and outbound tourists", based on the content and nature of tourism activities, it can be broadly divided into three categories: illegal acts, violations of social moral acts, and uncivilized acts. Among them, violations of social morality and uncivilized behavior are the main body of tourist vandalism.

(2) Correct attitude towards tourist vandalism. Attitude consists of three dimensions: perception (belief, knowledge and understanding), emotion (likes and dislikes), and behavior (participation). Attitude is an important factor affecting the behavioral intention (Zhang, 2018). In recent years, the publicity and education of the media and governments made a significant drop of outbound and domestic uncivilized behavior. This study found that behavioral attitudes are significantly affected by environmental awareness and subjective norms. In addition to the publicity and education of the media, knowledge of correct attitudes towards tourist vandalism should be incorporated into the education of family and schools, so that the society can understand the contents and harms of the vandalism, and make tourists ashamed of vandalism.

(3) Avoid repetition of past vandalism. People always act specific behaviors in a certain way, and as long as such behaviors have occurred in the past, the possibility of repetition is very high (Chang, 2003). The study realizes that past behavior is one of the important factors that influence behavioral intentions. Besides establishing a negative list of vandalism of outbound tourist destinations, we must know the occurrence probability of vandalism and how to make outbound tourists avoid those behaviors. It was reported by "United Daily News" that in the past ten years illegal touching and throwing food to animals, littering, and urination anywhere were the typical tourist vandalism in Taiwan. These behaviors should be targeted and educated before trip.

In addition, the study also found out that past behavior was significantly affected by environmental awareness. Under the economic reform, China is undergoing a structural adjustment of industries, and people's environmental awareness is changing from the mainstream social paradigm (DSP) to the new ecological paradigm (NEP). That is to say, Chinese has changed from simply pursuit of GDP and economic benefits to integration sustainable development of economic, environmental and social benefits. Although tourists' environmental awareness at this stage is weak in human exceptionalism (Lin et al., 2014), they can be trained and educated.

Acknowledgements. This work was supported by the project of China Postdoctoral Science Foundation (grant No. 2017M610976), Natural Science Foundation of China (grant No. 41871146, No. 4187208, No. 41601590). 


\section{REFERENCES}

[1] Ajzen, I. (1991): The theory of planned behavior. - Organizational Behavior and Human Decision Processes 50: 179-211.

[2] Ajzen, I., Fishbein, M. (2005): The Influence of Attitudes on Behavior. The Handbook of Attitudes. - Erlbaum, Ahwah, NJ, pp. 173-221.

[3] Armitage, C. J., Conner, M. (2001): Efficacy of the theory of planned behavior: A metaanalytic review. - British Journal of Social Psychology 40: 471-499.

[4] Bamberg, S. (2003): How does environmental concern influence specific environmentally related behaviors? A new answer to an old question. - Journal of Environmental Psychology 23: 21-32.

[5] Bamberg, S., Ajzen, I., Schmidt, P. (2003): Choice of travel mode in the theory of planned behavior: the roles of past behavior, habit, and reasoned action. - Basic and Applied Social Psychology 25(3): 175-187.

[6] Bhati, A. D. S. (2014): Stakeholder responses to vandalism at visitor attractions: A Singapore and Bangkok comparison. - Dissertation/Thesis, James Cook University Australia, pp. 9-21.

[7] Bhati, A., Pearce, P. (2016): Vandalism and tourism settings: An integrative review. Tourism Management 57: 91-105.

[8] Chang, C. Y., Cai, C. S., Weng, S. Y. (1995): An environmental cognition approach to the analysis of visitors' vandalism: A case study of Chung-Shan Park in the Taichung city. - Journal of Outdoor Recreation 8: 67-89.

[9] Chang, L., C, Sung, B. M. (2003): Why are recreational areas vandalized? A synthetic perspective from five theories. - Journal of Criminology 6: 283-300.

[10] Christina, K., MacKenzie, J., Wells, M. et al. (2004): An analysis of intentions to recycle household waste: the roles of past behavior, perceived habit, and perceived lack of facilities. - Journal of Environmental Psychology 24: 237-246.

[11] Cohen, S. (1973): Property Destruction: Motives and Meanings. - Architectural Press, London, pp. 23-53.

[12] Corral-Verdugo, V., Carrus, G., Bonnes, M. et al. (2008): Environmental beliefs and endorsement of sustainable development principles in water conservation. Toward a new human interdependence paradigm scale. - Environment and Behavior 40: 703-725.

[13] Crotts, J. C. (2003): Theoretical perspectives on tourist criminal victimisation. - The Journal of Tourism Studies 14: 92-98.

[14] Daunt, K. L., Harris, L. C. (2012): Exploring the forms of dysfunctional customer behaviour: a study of differences in servicescape and customer disaffection with service. - Journal of Marketing Management 28: 129-153.

[15] Duan, W. T., Jiang, G. R. (2008): A review of the theory of planned behavior. Advances in Psychological Science 16: 315-320.

[16] Dunlap, R. E. (2008): The new environmental paradigm scale: From marginality to worldwide use. - Journal of Environmental Education 40: 3-18.

[17] Dunlap, R. E., Van Liere, K. D. (1978): The "New Environmental Paradigm": A proposed measuring instrument and preliminary results. - The Journal of Environmental Education 9: 10-19.

[18] Fornell, C., Larcker, D. F. (1981): Structural equation models with unobservable variables and measurement error: algebra and statistics. - Journal of Marketing Research 18: 382-388.

[19] Fullerton, R. A., Punj, G. (2004): Repercussions of promoting an ideology of consumption: consumer misbehavior. - Journal of Business Research 57: 1239-1249.

[20] Gao, M. D., Hung, C. C., Huang, C. C. (2003): The ecotourism behavioral model. Journal of Outdoor Recreation 16: 23-48. 
[21] Greaves, M., Zibarras, L. D., Stride, C. (2013): Using the theory of planned behavior to explore environmental behavioral intentions in the workplace. - Journal of Environmental Psychology 34: 109-120.

[22] Hou, J. X., Guo, Z. R. (1998): Study on the relationship between environmental attitudes of park visitors' inappropriate behavior management strategies and identity. - Journal of Outdoor Recreation 11: 17-42.

[23] Hu, B., Fu, Y. X., Xiong, Y. B. (2014): The driving factors and the formation mechanism of tourists' intention participating in low-carbon tourism: Based on theory of planned behavior. - Journal of Business Economics 8: 64-72.

[24] Huang, X, T., Liu, C. (2016): Companion constraints on tourist behavior: A case study of Hongkong ocean park. - Human Geography 31: 128-135.

[25] Hwang, Y. H., Kim, S. I., Jeng J M. (2000): Examining the causal relationships among selected antecedents of responsible environmental behavior. - Journal of Environmental Education 31: 19-25.

[26] Ibitayo, O. O., Virden, R. J. (1996): Visitor and manager perception of depreciative behavior in urban park setting. - Journal of Park and Recreation Administration 14: 3651.

[27] Johnson, D. R., Kamp, M. E. V. (1996): Extent and control of resource damage due to noncompliant visitor behavior: A case study from the U. S. national parks. - Natural Areas Journal 16: 134-141.

[28] Kaiser, F. G., Gutscher, H. (2003): The proposition of a general version of the theory of planned behavior: predicting ecological behavior. - Journal of Applied Social Psychology 33: 586-603.

[29] Kaplan, S. (1983): A model of person-environment compatibility. - Environment and Behavior 15: 311-332.

[30] Lewin, K. (1951): Field Theory in Social Science. - Harper, New York, pp. 15-27.

[31] Li, H. M. (2007): Study on the Formation Mechanism of Rural Tourism Behavioral Intention Based on an Extended Theory of Planned Behavior Model. - Zhejiang University, Hang Zhou, pp. 48-58.

[32] Li, J. (2012): Review of research on uncivilized behavior of domestic tourists. - Journal of Management 25: 80-85.

[33] Li, M., He, C. P. (2002): Research on tourist uncivilized behavior. - Journal Beijing International Studies University 107: 26-28.

[34] Lin, M. S., Gong, F. H, Yuan, S. Q. (2014): Study on the relationship between environmental awareness and tourism behavior of tourists from Mainland to Taiwan. Fujian Tribune (Humanities and Social Science Edition) 5: 136-141.

[35] Lin, M. S., Zhao, D. X, Liu, L. H. (2016): Improved paths of tourists uncivilized behavior - based on the perspective of the theory of planned behavior. - Journal of Fujian Normal University (Natural Science Edition) 32: 152-159.

[36] López-Mosquera, N. (2016): Gender differences, theory of planned behavior and willingness to pay. - Journal of Environmental Psychology 45: 165-175.

[37] Luo, Y. J., Deng, J. Y. (2007): The new environmental paradigm and nature-based tourism motivation. - Journal of Travel Research 46: 392-402.

[38] McCaghy, C. H. (2008): Deviant Behavior: Crime, Conflict, and Interest Groups. Pearson/Allyn and Bacon, Boston, pp. 32-55.

[39] Mills, M. K., Bonoma, T. V. (1978): Deviant consumer behavior: a different view. Advances in Consumer Research 6: 347-352.

[40] Ouellette, J. A., Wood, W. (1998): Habit and intention in everyday life: the multiple processes by which past behavior predicts future behavior. - Psychological Bulletin 124: 54-74.

[41] Qiu, H. L. (2016): Study on the relationship moral norm and tourists' civilization tourism behavioral intention: An extended theory of planned behavior model. - Zhejiang Social Sciences 3: 96-103. 
[42] Qiu, H. L. (2017): Developing an Extended theory of planned behavior model to predict outbound tourists' civilization tourism behavioral intention. - Tourism Tribune 32: 75-86.

[43] Roth, C. E. (1992): Environmental Literacy: Its Roots, Evolution, and Directions in the 1990s. - ERIC/CSMEE Environmental Education, Columbus, Ohio, pp. 3-17.

[44] Wang, N. (2010): A research on Relationship between Tourists' Environmental Awareness and Environmental Behavior. - Tianjin University of Finance and Economics, Tianjin, pp. 22-31.

[45] Weaver, D. (2006): Sustainable Tourism: Theory and Practice. - Butterworth Heinemann, Oxford, pp. 31-47.

[46] Wu, M. L. (2009): Structural Equation Modeling. Operation and Application of AMOS. Chongqing University Press, Chongqing, pp. 95-121.

[47] Xie, T. (2016): Consumers' intention to visit green hotels: based on TPB perspective. Tourism Tribune 31: 94-103.

[48] Xu, C. (2014): Study on the tourist image of mainland in Taiwan media: "United Daily News" reported as an example. - Southeast Propagation 121: 24-28.

[49] Yang, T. H., Cheng, Y. Y. (2013): The influences of visitors' environmental attitude and situational factors on the occurrence of vandalism: A case study of littering in YangMing-Shan National Park. - Journal of Outdoor Recreation 26: 83-98.

[50] Zhang, C. J., Bai, K. (2015): A Study on the effect of face need on tourist inappropriate behavior. - Tourism Tribune 30: 55-65.

[51] Zheng, Q. J., Xu, A. X., Kong, D. Y. et al. (2018): Correlation between the environmental knowledge, environmental attitude, and behavioral intention of tourists for ecotourism in china. - Applied Ecology and Environmental Research 16(1): 51-62. 